\title{
Real-Time Harmonic Reduction using Synchronous PWM Control for Wound-Rotor Induction Motor
}

\author{
M. E. Abdel- Karim \\ Electrical Power and Machines Dept., Faculty of Eng. \\ Tanta University, EGYPT
}

\begin{abstract}
In this paper the dynamic performance of the wound rotor induction motor operating with synchronized modulator is considered and analyzed. The proposed modulator employs a PWM transistor-controlled capacitive network in rotor circuit with a carrier frequency proportional to the rotor voltage frequency. This modulator can reduce the harmonic current components of the motor and consequently improve the motor power factor. The reduction of these components is achieved instantaneously with no need for sensing or computing the harmonics current in motor current, thus simplifying the control system. Simulated and experimental results obtained from closed loop $0.5 \mathrm{KVA}$ prototype confirm the feasibility and features of the proposed system.
\end{abstract}

\section{Introduction}

Adjustable speed control of induction motor (IM). via static power converter is increasingly based on real time digital generation of PWM waveforms. Different strategies for optimizing PWM for voltage source inverter in the stator side of IM such as synchronous, asynchronous PWM and regular sampling have been proposed and analyzed [1-8]. However, controlling the speed of wound- rotor IM can be achieved by using external variable rotor resistance or by resonating the rotor circuit using uncontrolled reactive rotor network [9]. These systems provide high starting and braking torque, improved power factor and also reacts favorably to non-sinusoidal supply voltage. For smooth variation of motor speed, the reactive rotor networks have been controlled using thyristor switches [10-12]. Also, transistor switches strategy has been proposed using non- optimal PWM techniques [13-14]. These switches lead to significant increase of harmonic distortion in machine currents. Such high power PWM electronic switches are generally operated at low-switching frequency, owing to limitation of the semiconductor switches. This needs an optimization for the PWM switching sequences, aiming at a reduction of harmonic components of the machine currents, and a reduction in torque harmonics.

Manuscript received from Dr. M. E. Abdel-Karim

Accepted on : $26 / 3 / 2002$

Engineering Research Journal Vol 25, No 2, 2002 Minufiya University, Faculty of Engineering, Shebien El-Kom, Egypt, ISSN 1110-1180 


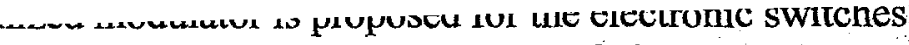
of the capacitive rotor network to control the speed of the wound rotor induction motor. This synchronized modulator is extended over a full fundamental period of the rotor voltage so that the switching of the capacitive rotor network is in synchronism with the rotor voltage frequency. The resulting pulse sequence exhibits quarter wave symmetry. Synchronized pulse sequences are advantageous in that the harmonic spectrum does not contain sub-harmonic components and minimize the low order harmonic distortion on the machine currents.

\section{System Description}

\section{2-1. Power circuit}

The schematic for the proposed synchronous PWM control for wound rotor IM is shown in Fig 1. Three capacitors are star connected to the rotor via a threephase power controller using four IGBT switches. $T_{1}$ and $T_{3}$ are shunt switches while $T_{2}$ and $T_{4}$ are series switches. Each transistor is fed through four fast recovery diode bridge to act as ac switch as shown in Fig 1.

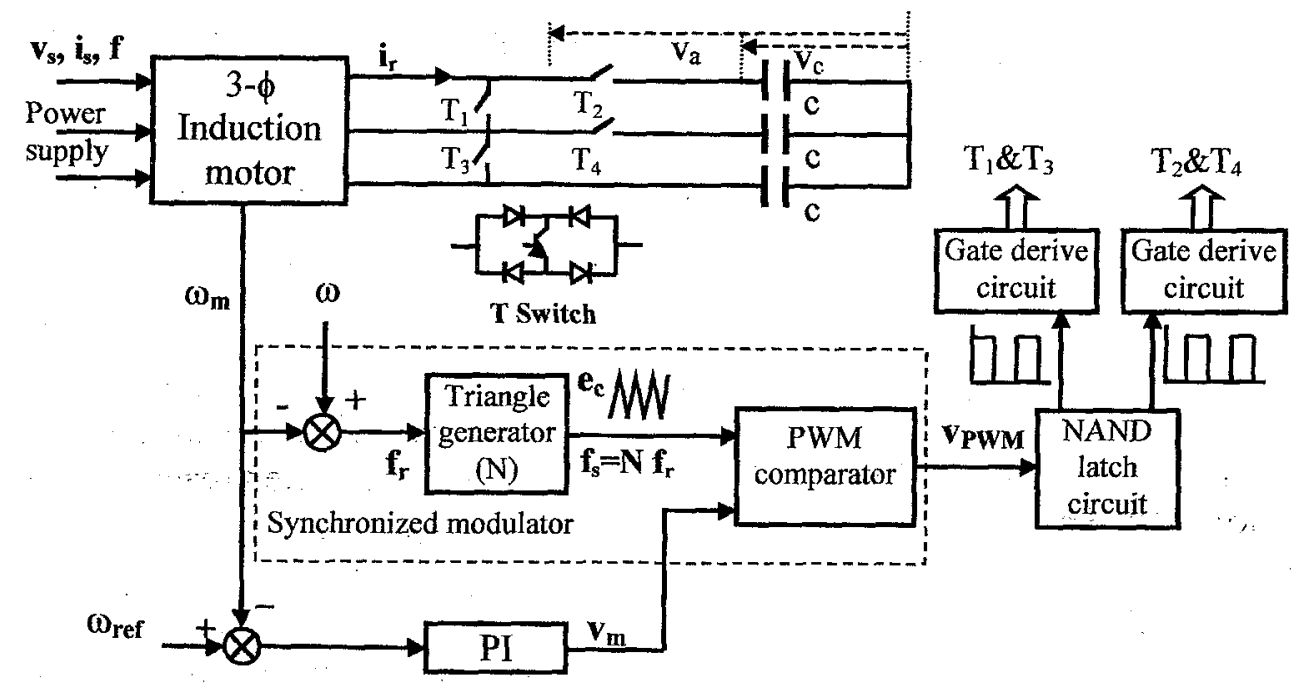

Fig. 1. Schematic diagram of the PWM with a synchronized carrier wave.

The switching process is to disconnect the capacitor (series switches are OFF while shunt switches are $\mathrm{ON}$ ) or connect these capacitors (shunt switches are OFF while series switches are $\mathrm{ON}$ ) in the rotor circuit. The motor rotates at its rated speed when shunt switches are continuously $O N$. While when the series switches are continuously $O N$, the capacitors are permanently connected to the rotor. To vary the motor speed over the whole range, the value of the capacitors is chosen by varying the duty cycle of the series switches from zero to $100 \%$ (i.e. from $100 \%$ to zero of the shunt switches), motor speed changes from its rated value to zero.

\section{2-2. Control circuit}

The control circuit of the system can be subdivided into synchronized modulator (for open and closed loop) and PI controller for closed loop speed 
regulation as shown in Fig 1. The synchronized modulator consists of a triangular carrier signal generator with output frequency $f_{s}$ which is synchronized with rotor voltage frequency $f_{\mathrm{r}}$ by a fixed frequency ratio $\mathrm{N}$. PWM comparator compares the synchronized-frequency carrier signal with a modulating signal $\mathrm{v}_{\mathrm{m}}$ (open or closed loop). The comparator provides a train of synchronized pulses with a duty cycle inversely proportional to $\mathrm{v}_{\mathrm{m}}$ and its frequency is the carrier frequency. The output of synchronized modulator is fed to the drive circuit through a NAND latch circuit. This circuit complements the synchronized pulses and ensures that, any group of series or shunt switches turned OFF just after the others are ON. The relative duty cycle of the series switches determines capacitor voltage level relative to that of the rotor and hence achieving the desired motor speed. The capacitor voltage increases due to increasing the duty cycle of series switches by reducing $v_{m}$ (open loop) or $\omega_{\text {ref }}$ (closed loop).

PI controller circuit for control of a power transistor, which operate in a high frequency chopping mode, such that the duty cycle can be smoothly controlled the motor speed $\omega_{\mathrm{m}}$ to the desired speed $\omega_{\text {ref }}$ in the range 0 to $100 \%$.

\section{Synchronized Modulator}

Two mathematical models have been proposed for modeling the switchedcontrol through the rotor of the induction motor $[15,16]$. These models are only restricted in time domain analysis. The frequency domain analysis will be used to study the motor behaviour with the proposed synchronized modulator. In the present study, the structure considered in Fig 1, is open loop feed forward system. Effectively, the capacitors can be considered as a voltage source $\mathrm{v}_{\mathrm{c}}$ connected to the rotor circuit and has the same rotor voltage frequency. Accordingly, the capacitor voltage $\mathrm{v}_{\mathrm{c}}$ is sinusoidal. The switch-on duration $T_{o n}$, Fig 2, of $v_{c}$ across the rotor circuit is $v_{a}$. Due to high switching frequency, the switched voltage $v_{a}$ can be approximated by a sequence of flattopped pulses with sinusoidal shape amplitude of $v_{c}$, since the variation of $v_{c}(t)$ in the switching duration will not be significant. Then, $\mathrm{v}_{\mathrm{a}}(\mathrm{t})$ can be written as,

$$
v_{a}(t)=\left\{\begin{array}{lll}
v_{c}(k T) & \text { for } & k T \leq t<k T+T_{s} \\
0 & \text { for } & k T_{s}+T_{\text {on }} \leq t<(k+1) T_{s}
\end{array}\right.
$$

where, $\mathrm{k}=0,1,2, \ldots \ldots \ldots \ldots \ldots \ldots$

$T_{s}$ is the period of switching frequency $f_{s}$.

The switched voltage $v_{a}^{*}(t)$ can be expressed as an infinite series,

$$
\mathrm{v}_{\mathrm{a}}^{*}(\mathrm{t})=\sum_{\mathrm{k}=0}^{\infty} \mathrm{v}_{\mathrm{c}}\left(k \mathrm{kT}_{\mathrm{s}}\right)\left[\mathrm{u}_{\mathrm{s}}\left(\mathrm{t}-\mathrm{kT} \mathrm{T}_{\mathrm{s}}\right)-\mathrm{u}_{\mathrm{s}}\left(\mathrm{t}-\mathrm{kT} \mathrm{T}_{\mathrm{s}}-\mathrm{T}_{\text {on }}\right)\right]
$$

where $u_{s}(t)$ is the unit-step function.

Taking the Laplace transform, S-domain, on both sides of eq (1), it follows that, 


$$
\mathrm{V}_{\mathrm{a}}^{*}(\mathrm{~S})=\sum_{\mathrm{k}=0}^{\infty} \mathrm{v}_{\mathrm{c}}(\mathrm{kT})\left[\frac{1-\mathrm{e}^{-\mathrm{S} \mathrm{t}_{\mathrm{on}}}}{\mathrm{S}}\right] \mathrm{e}^{-\mathrm{kST}}
$$

The term $\mathrm{e}^{-\mathrm{T} \text { on } \mathrm{S}}$ can be approximated by taking only the first two terms of its power-series expansion, then,

$$
1-\mathrm{e}^{-\mathrm{ST}_{\mathrm{on}}}=1-\left[1-\mathrm{ST}_{\text {on }}+\frac{\left(\mathrm{ST}_{\text {on }}\right)^{2}}{2 !}-\ldots \ldots . . . \mathrm{ST}_{\text {on }}\right.
$$

Thus, eq (2) is simplified to,

$$
\mathrm{V}_{\mathrm{a}}^{*}(\mathrm{~S}) \cong \mathrm{T}_{\mathrm{on}} \sum_{\mathrm{k}=0}^{\infty} \mathrm{v}_{\mathrm{c}}\left(k \mathrm{kT}_{\mathrm{s}}\right) \mathrm{e}^{-k S \mathrm{~T}_{\mathrm{s}}} \cong \mathrm{T}_{\mathrm{on}} \sum_{\mathrm{k}=0}^{\infty} \mathrm{v}_{\mathrm{c}}\left(k \mathrm{~T}_{\mathrm{s}}\right) \mathrm{z}^{-\mathrm{k}}
$$

In the Z-domain, eq (3) is equivalent to,

$$
\mathrm{V}_{\mathrm{a}}(\mathrm{z}) \cong \mathrm{T}_{\mathrm{on}} \mathrm{V}_{\mathrm{c}}(\mathrm{z})
$$

For the sinusoidal waveform, the Z-transform of $v_{c}(t)$ is [17],

Accordingly, eq (4) becomes,

$$
V_{c}(z)=\frac{z \sin \omega_{r} T_{s}}{z^{2}-2 z \cos \omega_{r} T_{s}+1}
$$

$$
\begin{aligned}
\mathrm{V}_{\mathrm{a}}(\mathrm{z}) & \cong \mathrm{T}_{\text {on }} \frac{\mathrm{z} \sin \omega_{\mathrm{r}} \mathrm{T}_{\mathrm{s}}}{\mathrm{z}^{2}-2 \mathrm{z} \cos \omega_{\mathrm{r}} \mathrm{T}_{\mathrm{s}}+1} \\
& \cong \mathrm{T}_{\text {on }} \frac{\mathrm{e}^{\mathrm{ST} \mathrm{T}_{\mathrm{s}}} \sin \omega_{\mathrm{r}} \mathrm{T}_{\mathrm{s}}}{\mathrm{e}^{2 S \mathrm{~T}_{\mathrm{s}}}-2 \mathrm{e}^{S \mathrm{~T}_{\mathrm{s}}} \cos \omega_{\mathrm{r}} \mathrm{T}_{\mathrm{s}}+1}
\end{aligned}
$$

where $\omega_{\mathrm{r}}=2 \pi \mathrm{f}_{\mathrm{r}}$ and $\mathrm{f}_{\mathrm{r}}$ is the rotor voltage frequency.

For steady state $S=j \omega_{r}$ and $T_{S}=1 / f_{s}$ then eq (5) becomes,

$$
V_{a}(z) \cong T_{\text {on }} \frac{e^{j 2 \pi \frac{f_{r}}{f_{s}}} \sin 2 \pi \frac{f_{r}}{f_{s}}}{e^{j 4 \pi \frac{f_{r}}{f_{s}}}-2 e^{j 2 \pi \frac{f_{r}}{f_{s}}} \cos 2 \pi \frac{f_{r}}{f_{s}}+1}
$$

For fixed-frequency carrier, varying $v_{\mathrm{m}}$ will vary each of motor speed $\omega_{\mathrm{m}}$, rotor voltage frequency $f_{r}$, and switch-on duration $T_{\text {on }}$. Accordingly, both the phase and magnitude of $\mathrm{V}_{\mathrm{a}}(\mathrm{z})$ will be varied. This leads to obtaining variable harmonic current components for each motor speed.

For the proposed modulator, with a fixed frequency ratio $N=f_{s} / f_{I}$, eq (6) becomes,

$$
\mathrm{V}_{\mathrm{a}}(\mathrm{z}) \cong \mathrm{T}_{\text {on }} \frac{\mathrm{e}^{\mathrm{j} 2 \pi / \mathrm{N}} \sin 2 \pi / \mathrm{N}}{\mathrm{e}^{\mathrm{j} 4 \pi / \mathrm{N}}-2 \mathrm{e}^{\mathrm{j} 2 \pi / \mathrm{N}} \cos 2 \pi / \mathrm{N}+1}
$$

The phase and magnitude of the division term in eq (7) become fixed with speed variation. However, the variation of $\mathrm{T}_{\text {on }}$ with motor speed will be studied as given below. 


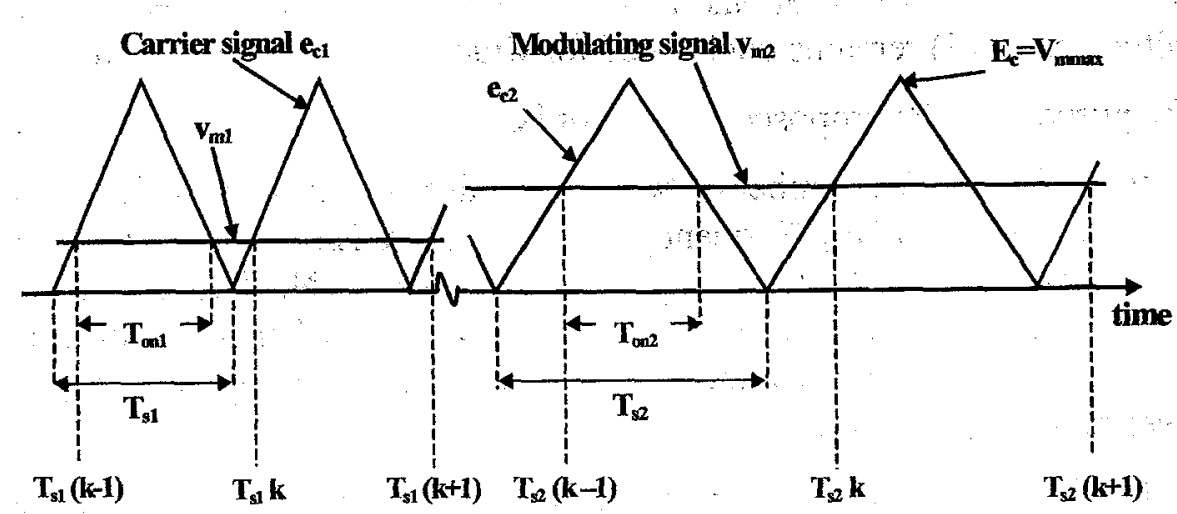

Fig. 2. Timing diagram of PWM with a synchronized-frequency carrier signal.

Figure 3 , shows the speed variation versus the reference voltage $v_{m}$ at certain capacitance $(\mathrm{c}=14 \mu \mathrm{F})$ for fixed and synchronized-frequency carriers with constant load torque. Such variations was measured primarily to evaluate the behaviour of motor speed with $\mathrm{v}_{\mathrm{m}}$. It is noticed that the motor speed is linearly varied with $v_{m}$ i.e. $\quad \omega_{m}=k^{\prime}\left(v_{m}-0.4\right)$

Accordingly, and from Fig 2 using triangles uniformity rule,

$$
\text { since, } \quad \begin{aligned}
\frac{\mathrm{T}_{\mathrm{on} 1}}{\mathrm{~T}_{\mathrm{sl}}} & =\mathrm{f}_{\mathrm{sl}} \mathrm{T}_{\mathrm{on} 1}=1-\frac{\mathrm{v}_{\mathrm{ml}}}{\mathrm{V}_{\mathrm{m} \max }} \\
\mathrm{f}_{\mathrm{s} 1} & =N \mathrm{Nf}_{\mathrm{r} 1}=\mathrm{Ns}_{1} \mathrm{f} \\
& =\mathrm{N}\left(\frac{\omega-\omega_{\mathrm{ml}}}{\omega}\right) \mathrm{f}=\mathrm{N}\left(1-\frac{\omega_{\mathrm{ml}}}{\omega}\right) \mathrm{f}
\end{aligned}
$$

where, the slip ' $\mathrm{s}_{1}$ ' is given by, $\quad \mathrm{s}_{1}=\left(\omega-\omega_{\mathrm{m} 1}\right) / \omega$, and $\mathrm{f}$ is the supply frequency.

From eq (8) and by considering the synchronous motor speed $\omega=k^{\prime}\left(V_{m \max }-0.4\right)$ for simplicity, eq (10) becomes,

$$
\mathrm{f}_{\mathrm{sl}}=\frac{\mathrm{N}}{\xi}\left(1-\frac{\mathrm{v}_{\mathrm{m} 1}}{\mathrm{~V}_{\mathrm{m} \max }}\right) \mathrm{f}
$$

and eq (9) becomes,

$$
\frac{\mathrm{N}}{\xi}\left(1-\frac{\mathrm{v}_{\mathrm{ml}}}{\mathrm{V}_{\mathrm{m} \max }}\right) \mathrm{f} \mathrm{T}_{\mathrm{onl}}=1-\frac{\mathrm{v}_{\mathrm{ml}}}{\mathrm{V}_{\mathrm{m} \max }}
$$

where, $\quad \xi=1-\frac{0.4}{V_{\mathrm{m} \max }}$

For a step change of speed reference voltage to $V_{\mathrm{m} 2}$ at steady state, eq (12)

becomes, $\quad \frac{N}{\xi}\left(1-\frac{v_{m 2}}{V_{m \max }}\right) \mathrm{fT}_{\mathrm{on} 2}=1-\frac{\mathrm{v}_{\mathrm{m} 2}}{\mathrm{~V}_{\mathrm{m} \max }}$

Dividing eq (12) by eq (13) gives, $\quad \mathrm{T}_{\text {on } 1}=\mathrm{T}_{\mathrm{on} 2}=\xi /(\mathrm{Nf})$

This means that, for the variation of speed reference voltage $v_{m}$ with constant load torque, the switch-on duration $\mathrm{T}_{\text {on }}$ remains unchanged, while the relative duty cycle vary to ensure capacitor voltage required to achieve the desired 
umvivi speed. With this result and tor constant frequency ratio $\mathrm{N}$, the phase and magnitude of eq (7) remains unchanged for wide range of motor speed.

So, the purpose of the proposed modulator is,

- to maintain the number of switching pulses for the rotor voltage always fixed, i. e. the switching frequency $f_{s}$ is in synchronism with the fundamental frequency of the rotor voltage $f_{r}$ by the frequency ratio $N$. The resulting pulse sequence exhibits quarter wave symmetry such that the harmonic spectrum of the rotor voltage does not contain sub-harmonic current component, especially at lower switching frequencies.

- to change the naturally variable phase and magnitude of the switched capacitor voltage $v_{a}$, eq (6), to fixed phase and magnitude, eq $(7)$ for wide range of motor speed. With this property of fixed phase and magnitude, the effect of the capacitor $c$, which can be optimally chosen at a certain speed and switching frequency to give minimum low order harmonic currents, remains valid for a wide range of motor speed.

\section{Mathematical Model}

Considering the per-phase equivalent circuit of the capacitor controlled IM refereed to the stator shown in Fig 4, the following motor equations can be written,

$$
\begin{array}{lll}
\mathrm{v}_{\mathrm{s}} & =\mathrm{i}_{\mathrm{s}} \mathrm{r}_{\mathrm{s}}+\ell_{\mathrm{s}}\left(\mathrm{di}_{\mathrm{s}} / \mathrm{dt}\right)+\mathrm{i}_{\mathrm{rm}} \mathrm{r}_{\mathrm{m}} & \\
\mathrm{i}_{\mathrm{rm}} \mathrm{r}_{\mathrm{m}} & =\ell_{\mathrm{m}}\left(\mathrm{di}_{\mathrm{m}} / \mathrm{dt}\right) & \\
\dot{\mathrm{i}}_{\mathrm{r}}^{\prime} & =\mathrm{i}_{\mathrm{s}}-\left(\ell_{\mathrm{m}} / \mathrm{r}_{\mathrm{m}}\right)\left(\mathrm{di}_{\mathrm{m}} / \mathrm{dt}\right)-\mathrm{i}_{\mathrm{m}} & \\
\mathrm{i}_{\mathrm{rm}} \mathrm{r}_{\mathrm{m}}=\mathrm{i}_{\mathrm{r}}^{\prime} \mathrm{r}_{\mathrm{r}}^{\prime} / \mathrm{s}+\ell_{\mathrm{r}}^{\prime}\left(\mathrm{di}_{\mathrm{r}}^{\prime} / \mathrm{dt}\right)+\mathrm{v}_{\mathrm{a}} & \\
\mathrm{v}_{\mathrm{a}}^{\prime}=0 & \text { if } T_{a} \text { ON and } T_{b} O F F \\
\mathrm{v}_{\mathrm{a}}^{\prime} & =\mathrm{v}_{\mathrm{c}}^{\prime} / \mathrm{s}, & \\
i_{\mathrm{r}}^{\prime} & =\mathrm{s}^{2} \mathrm{c}^{\prime}\left(\mathrm{dv}_{\mathrm{a}}^{\prime} / \mathrm{dt}\right) & \text { if } T_{a} O F F \text { and } T_{b} O N
\end{array}
$$

The developed motor torque is given by, $\quad \mathrm{T}_{\mathrm{m}}=3\left(\mathrm{I}_{\mathrm{r}}^{2} \mathrm{r}_{\mathrm{r}}^{\prime} / \omega_{\mathrm{m}}\right)$

The electromechanical equation is given by,

$$
\mathrm{J}\left(\mathrm{d} \omega_{\mathrm{m}} / \mathrm{dt}\right)=\mathrm{T}_{\mathrm{m}}-\mathrm{T}_{\mathrm{L}}-\beta \omega_{\mathrm{m}}
$$

Equations (15) to (22) have been used in ref (13) to calculate the motor performance under the condition of fixed-frequency carrier. In the present study the same equations are reprogrammed along with the following equations to simulate the system with the proposed modulator. The triangle carrier signal $e_{c}(t)$ of the synchronized PWM can be expressed by Fourier analysis as,

$$
e_{c}(t)=\left[1+\frac{8}{\pi^{2}} \sum_{n=1,3,5, \ldots}^{\infty} \frac{1}{n^{2}}(-1)^{\frac{(n-1)}{2}} \sin n \omega_{s} t\right] E_{c} / 2
$$

Where $E_{c}$ is the peak value of the triangular carrier signal and $\omega_{s}=2 \pi \mathrm{Ns} \mathrm{f}$ is its angular frequency. The maximum value $\mathrm{V}_{\mathrm{mmax}}$ of the modulation degree is adjusted to be equal to $E_{c}$ to provide modulation degree $M=V_{\operatorname{mmax}} / E_{c}=1$. 
Comparing $e_{c}(t)$ with $v_{m}(t)$ yields the switching pattern and PWM comparator V

$$
\begin{aligned}
& V_{P W M}=V_{c c} \text { for } \quad e_{c}(t)>v_{m}(t)>0 \quad T_{a} \text { OFF and } T_{b} O N \\
& =0 \quad \text { for } \quad e_{c}(t)<v_{m}(t)>0 \quad T_{a} O N \text { and } T_{b} \text { OFF }
\end{aligned}
$$

Generally, with synchronized PWM modulator, $V_{P M W}(t)$ will be a periodical function with the fundamental frequency.

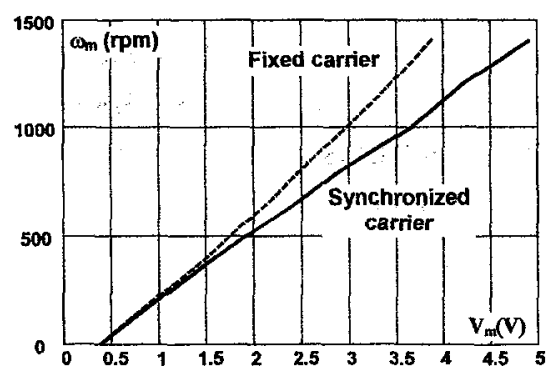

Figure 3. Measured motor speed $\omega_{m}$ variation with the speed reference voltage $v_{m}$.

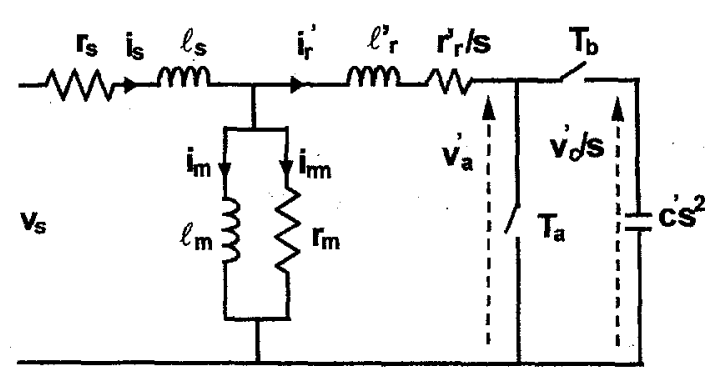

Fig. 4. Per phase motor equivalent circuit.

\section{Experimental Setup}

The experimental setup is illustrated in Fig 1 and was developed to test the proposed synchronized modulator for controlled wound rotor IM. The synchronized modulator is a very simple replacement of the conventional analog triangle regulator by triangular generator of FET type. The shunt $\left(\mathrm{T}_{1}\right.$ and $T_{3}$ ) and series $\left(T_{2}\right.$ and $T_{4}$ ) switches are IGBT switches of type 25Q101 $\left(\mathrm{V}_{\mathrm{CEO}}=1500 \mathrm{~V}, \mathrm{I}_{\mathrm{C}}=50 \mathrm{~A}\right)$. An analog current controlled separately excited dc motor provides the required load torque. Parameters of employed induction and dc machines are listed in the Appendix. A PC Pentium is used to program the Lab-pc $1200 \mathrm{I} / \mathrm{O}$ card using the LabView software to display experimental data. The interface between the I/O card and the system was done via a Hall effect sensors (LA25 and LV25 from LEM) for measuring the stator and rotor phase currents and voltages, respectively. A tacho-generator with a gain $2 \mathrm{~V} / 1000 \mathrm{rpm}$ is employed for measuring the instantaneous motor speed as well as for the feedback signal. The tacho-generator output is directly connected to the $\mathrm{I} / \mathrm{O}$ card. The parameters for the $\mathrm{PC}$ controller $(\mathrm{kp}+\mathrm{ki} / \mathrm{s})$ were adjusted empirically by means of computer simulation for a certain operating point (at $66 \%$ of rated speed $=1000$ r.p.m). The constant $\mathrm{k}_{\mathrm{p}}$ for proportional controller was adjusted to 20 , and the integrator $\mathrm{k}_{\mathrm{i}}=80 \mathrm{~s}^{-1}$ was used to obtain $5 \%$ overshoot of motor speed within $100 \mathrm{~m}$-sec.

\section{Simulation and Experimental Results}

Several computer simulations and experiments were run with different operating points in order to check the performance of synchronized modulator with closed loop system. Equations (15) to (25) listed above were solved using software Matlab-Simulink to obtain the motor performance under the proposed 
modulator. Figures 5 and 6 show the simulated motor speed and current waveforms at the same conditions without and with the synchronized modulator, respectively. These results were taken using PI controller at different step reference voltages at $0.75 \mathrm{~N}-\mathrm{m}$ load torque. The motor speeds follow the reference voltages and the steady state error for each reference is zero as shown in Figs $5 a$ and $6 \mathrm{a}$. Figure $6 \mathrm{a}$ ensures that the synchronized modulator makes the motor speed arrive rapidly to the reference than in Fig 5a.

Figures $5 \mathrm{~b}$ and $6 \mathrm{~b}$ show expanded waveforms of the applied voltage $\mathrm{v}_{\mathrm{s}}$, stator current $i_{s}$ and referred rotor current $i_{r}$ before the sudden change of the speed reference $\omega_{\text {ref }}$ from 1200 to $800 \mathrm{rpm}$. It is seen from these figures that the currents $i_{s}$ and $i_{r}$ are sinusoidal due to the used synchronized modulator.
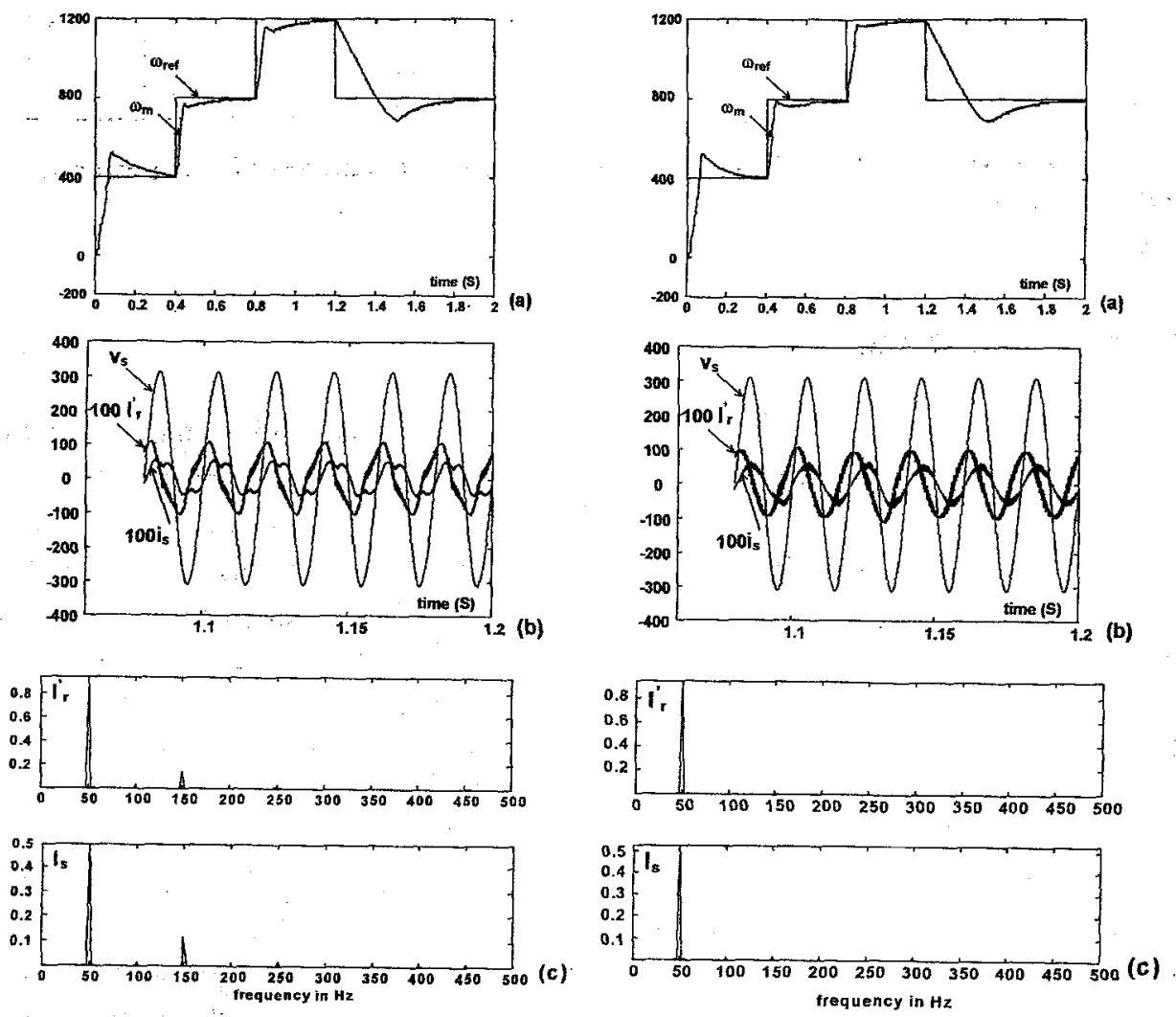

Fig. 5. Simulation results for closed loop motor control with fixed-frequency switching.

Fig. 6. Simulation results for closed loop motor control with synchronized-frequency switching.

Linear scales plot of $I_{r}$, and $I_{s}$ spectra without and with the synchronized modulator are shown in Figs $5 \mathrm{c}$ and $6 \mathrm{c}$, respectively. The results clarify the effect of the synchronized modulator in reducing the motor current harmonics produced by the fixed-frequency switching.

Figures 7 and 8 show the experimental waveforms of $\mathrm{v}_{\mathrm{s}}, \mathrm{i}_{\mathrm{s}}, \mathrm{v}_{\mathrm{a}}$, and $\mathrm{i}_{\mathrm{r}}$ at closed loop motor control for a sudden change of speed reference $\omega_{\text {ref }}$ and constant load torque. In Fig 7 the speed changes from 1200 to 1040 rpm with fixed switching frequency $f_{s}$ is $900 \mathrm{~Hz}$. This low switching frequency is chosen at $1200 \mathrm{rpm}$, i.e. $\mathrm{f}_{\mathrm{r}}$ is $10 \mathrm{~Hz}$, and the stator voltage $\mathrm{v}_{\mathrm{s}}$ is reduced to $190 \mathrm{~V}$ to have 
significant current harmonics and small-sustained oscillations in the motor current waveform as shown in Figs $7 \mathrm{~b}$ and $7 \mathrm{~d}$. These harmonics and oscillations are increased dramatically. when the speed is decreased to $1000 \mathrm{rpm}$, i.e. $\mathrm{f}_{\mathrm{r}}$ increased to $16.667 \mathrm{~Hz}$ while the switching frequency remains without change at $900 \mathrm{~Hz}$.
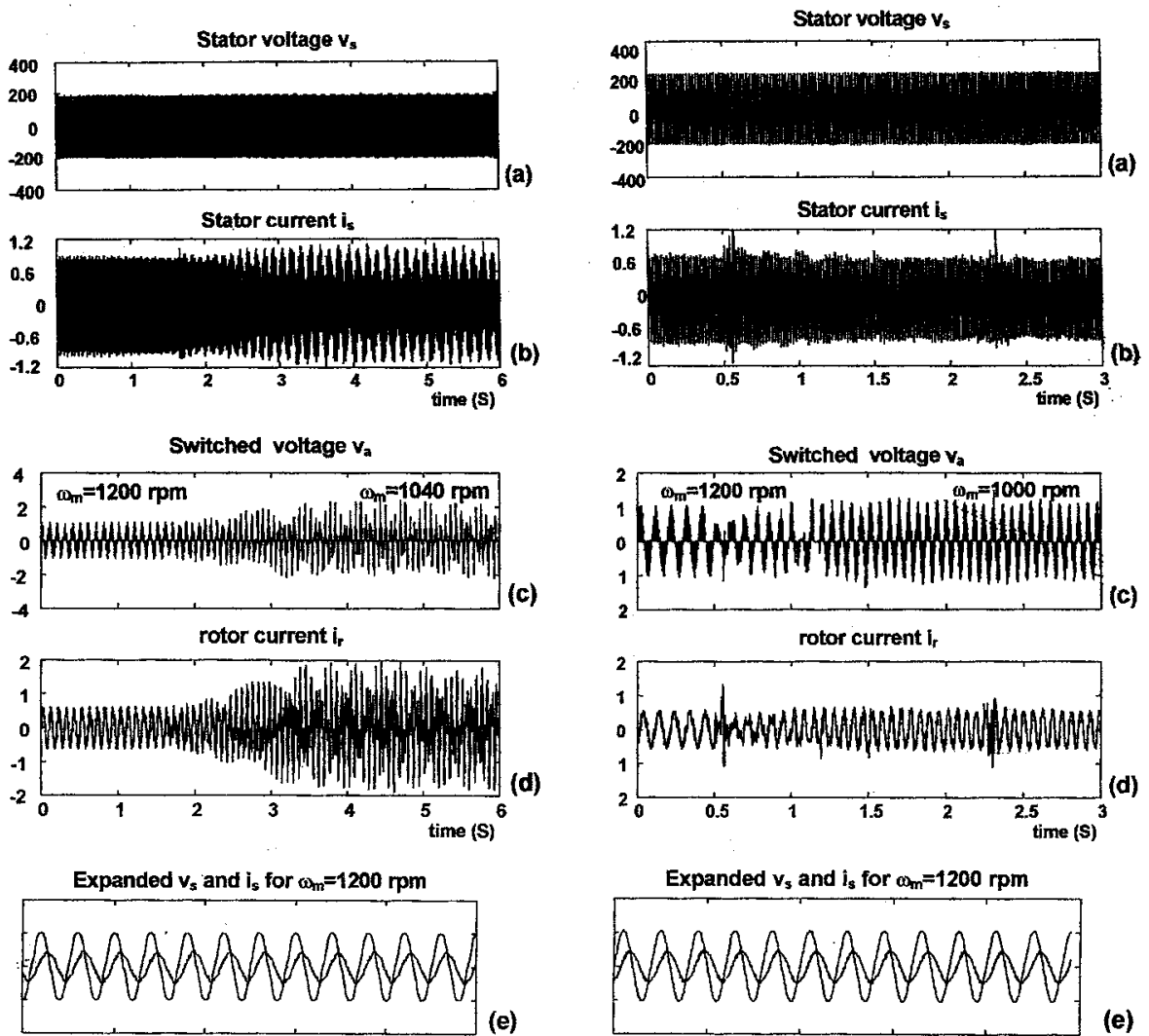

(e)
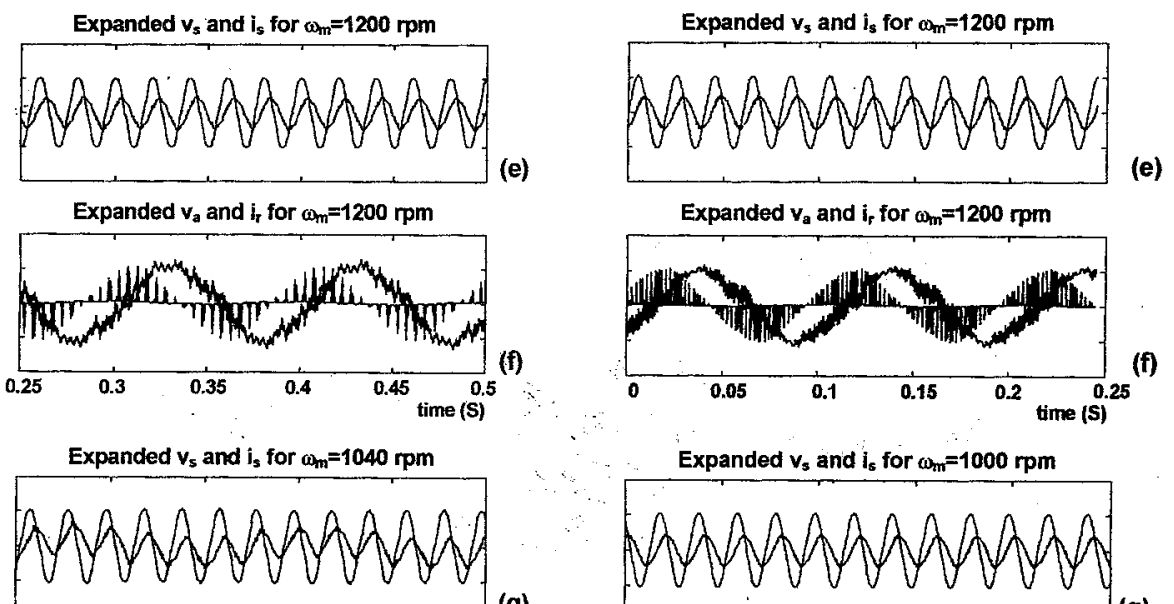

(g)
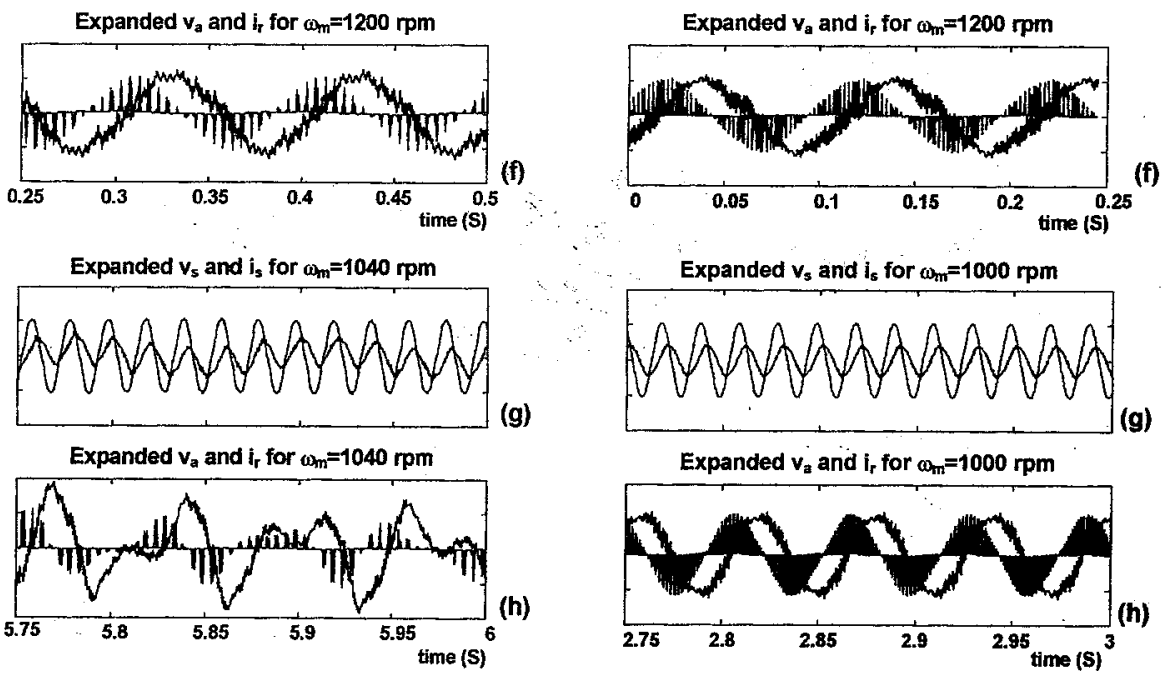

Fig. 7. Experimental results for closed loop motor control with fixed-frequency switching for speed reference variations at constant load and $V_{s}=190 \mathrm{~V}$.

Fig. 8. Experimental results for closed loop motor control with synchronizedfrequency switching for speed reference variations at constant load and $V_{3}=220 V$. 
In Fig 8, the synchronized modulator with fixed frequency ratio $\mathrm{N}$ of 90 is used. This ratio can be changed to the values with only a small adjustment in triangle generator shown in Fig 1 . Figure 8 shows the system response, since the motor speed is varied from 1200 to $1000 \mathrm{rpm}$ with $\mathrm{v}_{\mathrm{s}} 220 \mathrm{~V}$. Accordingly, $\mathrm{f}_{\mathrm{r}}$ is varied from 10 to $16.667 \mathrm{~Hz}$, consequently the synchronized modulator adapt $f_{s}$ from 900 to $1500 \mathrm{~Hz}$ respectively. As expected from the analysis of the proposed modulator and referring to eq (7), where the phase and magnitude of $\mathrm{v}_{\mathrm{a}}$ remains unchanged, the motor current waveforms remain sinusoidal in the steady state for both speeds of 1200 and $1000 \mathrm{rpm}$. This is true except with high switching ripple super-imposed on the motor currents

Figure 9 shows the experimental waveforms of $\mathrm{i}_{\mathrm{Lref}}, \omega_{\mathrm{m}}, \mathrm{v}_{\mathrm{a}}$, and $\mathrm{i}_{\mathrm{i}}$ for closed loop motor control with synchronized switching frequency with step change of load torque at constant reference speed. Figures $9 \mathrm{e}$ to $9 \mathrm{~h}$ show that, the steady state motor currents remain nearly sinusoidal before and after loading. These results according to eq (7) where only the phase of $\mathrm{v}_{\mathrm{a}}$ remains unchanged while its magnitude is continuous variation due to the dependency of $T_{\text {on }}$ on load value. This leads to the nearly sinusoidal appearance.
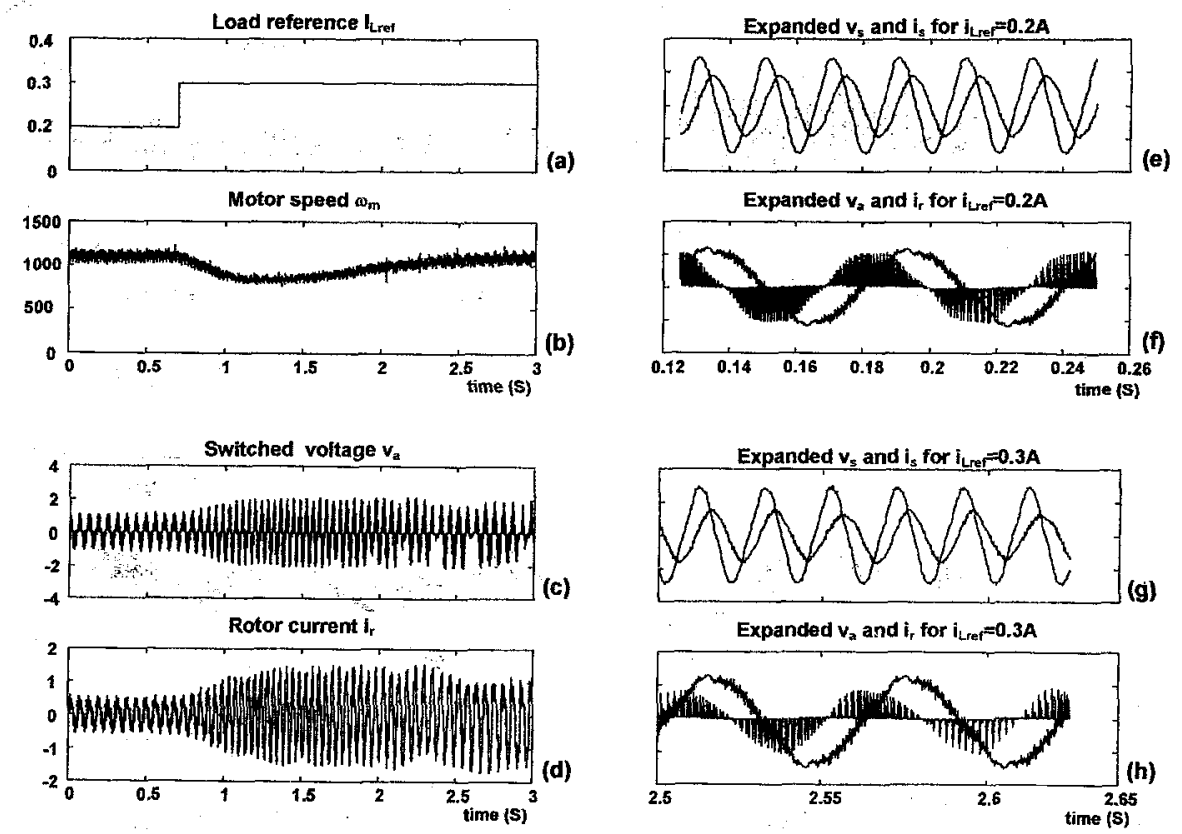

Fig. 9. Experimental results for closed loop motor control with synchronized switching frequency for load variation with constant speed reference at $V_{s}=220 \mathrm{~V}$.

\section{Conclusions}

The present paper deals with the implementation of a synchronized PWM in conjunction with closed-loop control of wound rotor IM. The synchronized modulator has employed a PWM: transistor-controlled capacitive network in rotor circuit with a carrier frequency proportional to the rotor voltage frequency. It has been shown that, the modulator maintain the number of switching pulses for the rotor voltage always fixed which exhibit quarter wave 
symmetry and reduce the sub-harmonic current component, especially at lower switching frequency. The mathematical analysis shows that, the naturally variable phase and magnitude of the switched capacitor voltage has been changed to fixed phase and magnitude for wide range of motor speed. With this property, the effect of the rotor capacitor, which can be optimally chosen at a certain speed and switching frequency to give minimum low order harmonic currents, remains valid for a wide range of motor speed. A power factor improvement is necessarily obtained by this harmonic content reduction. Simulations and experimental results have been shown to be in good agreement with the mathematical analysis.

The proposed modulator is also valid for the PWM inverter feeding the stator of the ac drives recently developed with vector control, direct torque, and space vector techniques. These techniques have the same drawbacks of the system under consideration when using a fixed-frequency switching that affects the drive performance.

\section{References}

1] S. R. Bowes, "Advanced regular-sampled PWM control techniques for drives and static power converters", IEEE Trans. on Industrial Electronics, vol. 42, no.4, Aug. 1995. pp 367-373.

2] J. Holtz and B. Beyer, " Optimal synchronous pulse width modulation with a trajectorytracking scheme for high-dynamic performance", IEEE Trans. on Industry Applications, vol. 29, no. 6, Nov/Dec. 1993. pp1098-1105

3] J. Hamman and L. P. Du Toi, "A New micro-computer controller modulator for PWM inverters", IEEE Trans. on Industrial Applications, vol. IA-22, no. 2, March/April 1986. pp281-285.

4] Y. Iwaji and S. Fukuda, "A pulse frequency modulated PWM inverter for induction motor drives", IEEE Trans. on Power Electronics, vol.7, no. 2. April 1992. pp404-410.

5] J. Richardson, and O. T. Kukrer, "Implementation of a PWM regular sampling strategy for AC drives", IEEE trans. on Power Electronics, vol. 6, no.4, October 1991. pp 645-655.

6] S. R. Bowes, 'Novel real-time harmonic minimized PWM control for drives and static power converters", Applied power Electronics Conference and Exposition, APEC' 1993. pp 561-567

7] S. R. Bowes, "Efficient microprocessor real-time PWM drive control using regular-sampled harmonic minimization techniques", IEEE Industrial electronics, ISEI' 93, Budapest, 1993. pp 211-218.

8] J. C. SALMAN, "Selecting stepped reference wave forms for PWM inverter drives to minimize the current distortion", IEEE Industry Applications Society Annual Meeting, vol. 1, 1990. pp 703-710.

9] J. Reinert and G. Parsley, "Controlling the speed of an induction motor by resonating the rotor circuit", IEEE trans. on Industry Applications, vol.31, no. 4, July / August 1995. pp 887-891.

10] M. Ramamooryty, and M. Arunachalam, "Dynamic performance of a closed loop Induction motor speed control system with phase controlled SCR' $s$ in rotor", IEEE Trans. on Industrial Applications, vol. IA-15, no. 5, Sept./Oct. 1979. pp 484-493.

11] S. Lesar, M. S. Smiai, and W. Shephert, "Control of wound rotor induction motor using thyristor in the secondary circuits", IEEE Trans. on Industrial Applications, vol. 32, no. 2, March/April 1996. pp 335-344

12] A. El-Sabbe, M. E. Abdel-Karim, and F. E. Abdel-Kader, "A new thyristor control for wide and stable speed variation of induction motors," MEPCON' 98, Mansoura, Egypt, Dec. $15-17,1998$. pp. $585-592$ 
13] A. E. Lashine, S. M. R. Tahoun, and F. A. saafan, "A new approach to the speed control of wound rotor induction motors", Alexandria Engineering Journal, vol. 38, no. 3, May 1999. pp. B75-B85

14] S. A. Mahmoud, A. E. Lashine, and S. A. Hassan, "Torque / speed control of wound rotor induction motors using a dc chopper circuit", Electric machine and Power System, vol. 11, 1986. pp 25- 38

15] C. S: Moo, C. C. Wei, and C. L. Huang, "Hybrid model for dynamic simulation of solidstate controlled induction machine", Electric Machine and Power Systems, vol. 17, 1989. pp 269-282

16] C. T. Liu, and W. L. Chang, "A generalized technique for modeling switch-controlled induction machine circuits", IEEE Trans. on Energy conversion, vol. 7, no. 1, March 1992. Pp168-176

17] B. C. Kuo, "Digital control systems" Saunders College Publishing, 1992. (Book)

\section{Appendix}

- Specification of tested induction motor:

$$
\begin{array}{ll}
\mathrm{V}_{\mathrm{s}}=220 \mathrm{~V}, & 2 \mathrm{p}=4, \\
\mathrm{n}_{\mathrm{m}}=1340 \mathrm{rpm}, & \mathrm{I}_{\mathrm{s}}=1.16 \mathrm{~A} .
\end{array}
$$

Appropriate calculations of no load, locked rotor tests, and open circuit tests gave the following results:

$$
\begin{aligned}
& r_{\mathrm{s}=35 \Omega} \quad \ell_{\mathrm{s}}=0.17 \mathrm{H} \\
& \ell_{\mathrm{r}}=0.0106 \mathrm{H} \quad r_{\mathrm{m}}=3400 \Omega \\
& \text { Primary } / \text { secondary transformation ratio }-4 \\
& \beta=0.00075 \mathrm{~N}-\mathrm{m} / \mathrm{rad} / \mathrm{sec} . \\
& J \text { (motor-load inertia) }=0.00035 \mathrm{~N} . \mathrm{m} / \mathrm{rad} / \mathrm{sec}^{2} .
\end{aligned}
$$$$
r_{\mathrm{r}}=2.1 \Omega
$$

- Specifications of separately excited dc machine: $220 \mathrm{~V}, 1.2 \mathrm{~A}, 1500 \mathrm{rpm}$ and field voltage is $220 \mathrm{v}$. 
تقليل التوافقيات الناتجة عن التحكم فى سرعة الخركات التأثيرية ذات العضو الدائري الملفوف باستخدام معدل نبضات تذامنى

$$
\begin{aligned}
& \text { د/ مصطفى السيد عبد الكريم } \\
& \text { قسم هندسة القوى والآلات الكهربية } \\
& \text { كلية المندسة - جامعة طنطا }
\end{aligned}
$$

\section{ملخص البحث}

تعتبر دوائر القدرة الإلكترونية المصدر الرئيسي للتوافقيات في أنظمة التسيير الكهربي. ويقدم هـــذا البحســـ

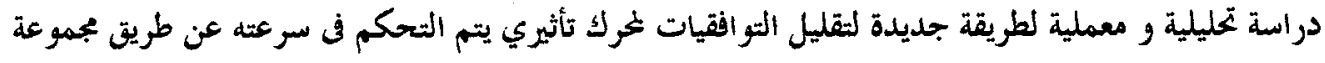

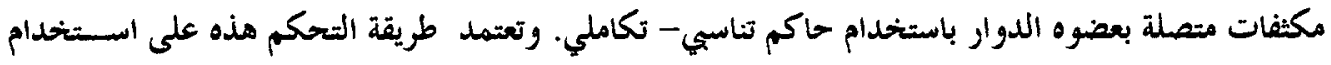

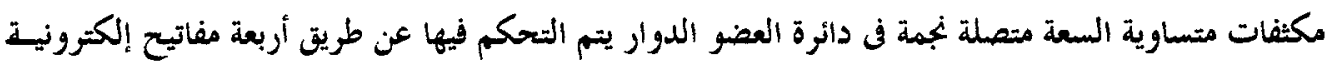

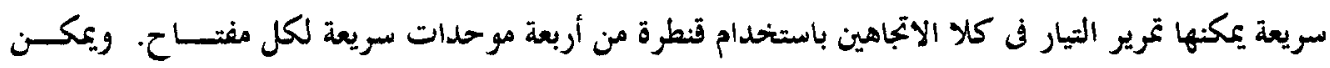

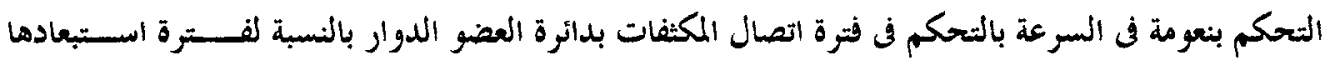

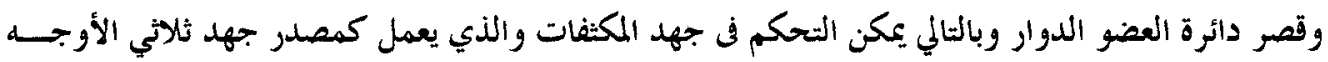

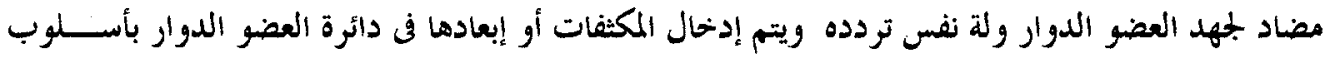
التعديل النبضي لموجة جهد المكتفات.

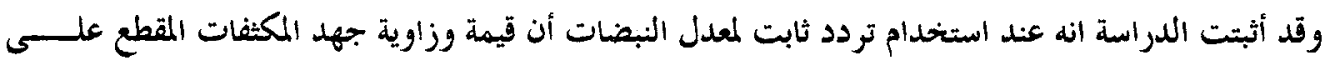

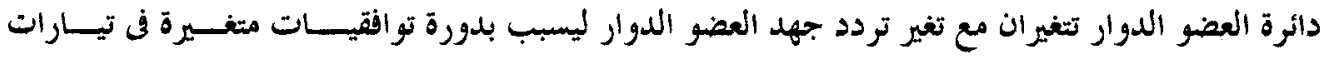

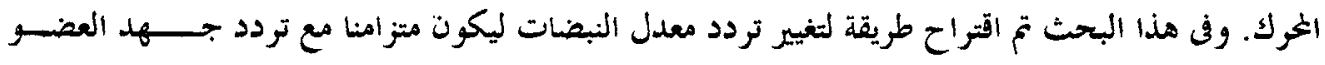

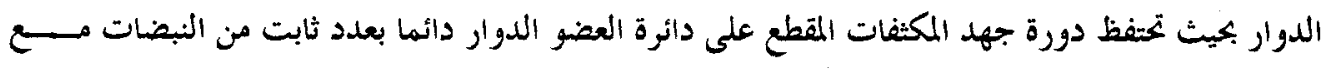

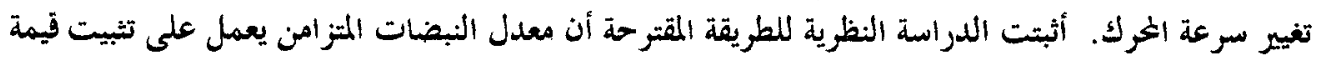

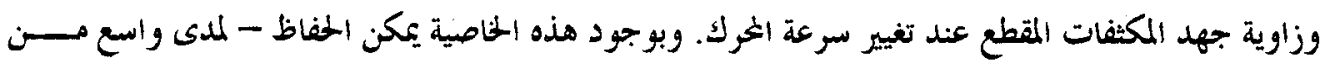

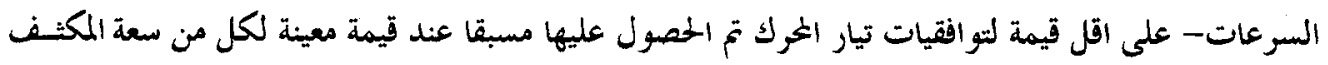

$$
\text { وتردد الثقطيع وسرعة المركك. }
$$

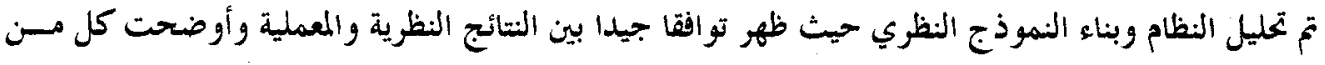

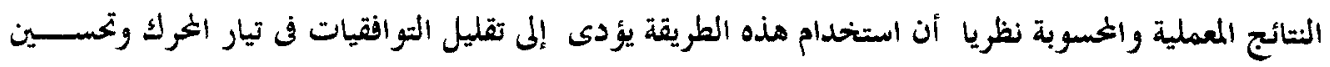
معامل القدرة مقارنتا باستخدام معدل نبضات ذو تردد ثابت المبات 